\title{
Low birth weight among term newborns in Wolaita Sodo town, South Ethiopia: a facility based cross-sectional study
}

\author{
Samson Kastro ${ }^{1 *}$, Tsegaye Demissie ${ }^{1}$ and Bereket Yohannes ${ }^{1,2,3}$
}

\begin{abstract}
Background: In low income countries, many low birth weight newborns often miss the chance for survival sooner or later. Others who survive would also face increased risks in later life. Though not adequately documented in Ethiopia, maternal factors pose the main risk. This study was aimed to estimate the proportion of low birth weight among term singletons without congenital malformations and factors associated with it in Wolaita Sodo town in South Ethiopia.

Methods: We did a facility based survey involving 432 postpartum women with their term newborns. Data was collected through face to face interview from March to April in 2016. The outcome measure was newborn birth weight. Bivariate logistic regression was applied to look for crude associations. Multivariate logistic regression analysis was done to adjust for potential confounders to identify independent predictors. Adjusted Odds Ratio (AOR) and 95\% confidence intervals $(\mathrm{Cl})$, and statistical significance at $P<0.05$ were reported.

Results: The proportion of term low birth weight was $8.1 \%$ in the study area. Women who had less education $(\mathrm{AOR}=6.23 ; 95 \% \mathrm{Cl}=1.68,23.1)$, house wives $(\mathrm{AOR}=5.85 ; 95 \% \mathrm{Cl}=1.40,24.3)$ and not frequently consuming fruits during pregnancy (AOR 11.3; $95 \% \mathrm{Cl}=1.98,64.9$ ) had a higher risk of having term low birth weight newborns. We documented a lesser odds of those from rural settings to have low birth weight newborns as compared to their counter urban equivalents ( $\mathrm{AOR}=0.06 ; 95 \% \mathrm{Cl}=0.006,0.6$ ).

Conclusions: Dietary counselling to pregnant mothers specific diet and nutrition including fruit diets in particular might contribute to reduce the risk of term low birth weight. Better education might have enabled women to prefer diets and their job engagements might also have capacitated them to decide on dietary preferences.
\end{abstract}

Keywords: Low birth weight, Term singletons, Wolaita Sodo, Ethiopia

\section{Background}

If a newborn weighs less than $2500 \mathrm{~g}$ at birth, it is termed as low birth weight (LBW) [1]. A low birth weight carries an increased risk of death on the newborns early in life or exposes to multiple health and development challenges later. The burden of immediate health problems on low birth weight newborns has been relatively widely documented in many low income countries with national demographic surveys [2].

An estimated 13\% all babies each year in Sub-Saharan Africa (SSA) are born LBW [3-6]. According to the

\footnotetext{
* Correspondence: tasamsona@gmail.com

${ }^{1}$ School of Public Health, Wolaita Sodo University, Wolaita Sodo, Ethiopia Full list of author information is available at the end of the article
}

Ethiopian Demographic and Health Surveys an estimated $13-11 \%$ of all babies in the country are born low birth weight $[7,8]$. The proportions have been documented with a wide variation across the different settings in the country. The prevalence has so far documented as low as 6.3 to 28 . $3 \%$ across Ethiopia [7-13]. Thus the national prevalence of low birth weight has remained high in Ethiopia.

In Ethiopia, most commonly used data on birth weight of the newborns are often based on national survey indirect indicators. However, the national data is known for its limitations including sampling strategies which would not be assumed to be representative of the socio-economic disparities and cultural diversities across the country. Though the proportion of skilled childbirth attendance is 
increasing in Ethiopia, we lack adequate evidence on maternal factors which would potentially predict birth outcomes of the newborns. This is so limited particularly in South Ethiopia which is characterized by a diverse culture and dietary practices. Thus the proportion of low birth weight in health facilities has been least documented in South Ethiopia.

A densely populated Wolaita area in south Ethiopia [14-19], many households often suffer from chronic food insecurity [20]. Thus even at times of crop harvest, many children in the area remain undernourished. However, we have very limited evidence on child health and nutritional status predictors particularly attached to maternal health during pregnancy and child births. Thus the main aim of this study was to estimate the proportion of low birth weight among term singletons that were born without congenital malformations in Wolaita Sodo town in South Ethiopia. It was also further aimed to identify sociodemographic and maternal factors associated with the outcome. The findings might help for local community based interventions to improve birth outcomes, and also expected to add on the existing knowledge.

\section{Methods}

\section{Study setting}

Wolaita Sodo town is an administrative capital for the Wolaita zonal administration in South Ethiopia. It is located at $380 \mathrm{~km}$ south from Addis Ababa. The town has 3 sub-cities; 11 lower administrative units. It had a census projected population of 110,$659 ; 48 \%$ were female.

One government hospital and another private one, 3 health centres, 11 health posts and 21 other private health facilities deliver health services to the population in the town. Out of all facilities; only health centres and hospitals are staffed to attend skilled childbirth [21]. Based on the local health service administrators' report for 2014/15, about 5000 childbirths were attended in government's health facilities at Wolaita Sodo town.

\section{Study design and period}

We did a facility based cross-sectional study involving postpartum mothers and their newborns through birth records from March to April in 2016.

\section{Population and sampling}

All postpartum mothers and their newborns in government health facilities in Wolaita Sodo town were the source population. Consecutively recruited 432 mother-newbornpairs were studied. Term newborns (born at 37 weeks or later of gestation) and singletons were included. Birth outcomes such as congenital malformations, multiple births, and stillbirths, and postpartum mothers with unknown last normal menstrual period were excluded.
A sample size of 451 was calculated with the following assumptions: $22.5 \%$ expected proportion of low birth outcome which was taken from similar Ethiopian study [13], 95\% confidence level, 5\% margin of error, and 10\% noneresponse consideration. It was proportionally allocated to government health facilities in Wolaita Sodo town based on number of previous childbirth attendance. Finally all eligible postpartum mother- to-child pairs were consecutively recruited until subsamples for the facilities and the total sample for the study were achieved.

\section{Variables and measurements \\ Outcome}

Birth weight of a term singleton newborn was an outcome measure. It was considered low birth weight if the newborn weighed less than $2500 \mathrm{~g}$. Birth weight measurement was taken within an hour after birth [1].

\section{Exposure variables and covariates}

Socio-demographic and socio-economic: maternal age, educational status, occupation, residence, family income and newborn's sex [22].

Diets and supplements: consumption of any additional meals and supplements such as iron and folic acid during pregnancy [23].

Maternal morbidity and previous obstetric histories: history of hypertension, diabetes mellitus and infections during pregnancy [24], pregnancy intervals, number of childbirth, low birth weight, abortions, and stillbirths [24].

Maternal health service utilization: antenatal care (ANC), gestational age at first ANC visit, and dietary counselling in ANC $[22,23]$. Whereas, a woman needs to make at least four ANC visits during pregnancy [25, 26].

Maternal nutritional status: Mid Upper Arm Circumference (MUAC) of mothers. Whereas, MUAC less than $23 \mathrm{~cm}$ centimetres defined the women as undernourished [27].

\section{Data collection}

We adopted a structured questionnaire from relevant articles and related literatures (Additional file 1) [7, 13]. The questionnaire was pretested in 23 respondents which were later not included to the main study. Four data collectors were trained on: the different modules of the questionnaire, participants' selection, maternal MUAC and birth weight measurements, and ethics.

Anthropometric measures were standardised for Technical Errors against an expert measurer. Weights of newborns were measured within an hour after birth with a digital weight scale. The MUAC of mothers was measured by using a none-stretchable tape.

\section{Statistical analysis}

Data were entered, cleaned and analyzed by using SPSS version 20. Descriptive statistics were done for the main 
variables. Through binary logistic regression analysis we selected exposure variables with a crude association to the outcome. The multivariate candidate variables were prioritized by using a yardstick cut-off point for statistical significance on bivariate analysis. Thus exposures and covariates with $p$-value less than 0.25 were taken for multivariate analysis. Finally, a multivariate logistic regression analysis was done to control for potential confounders and identify independent predictors of the outcome. Accordingly, we reported AORs as effect measures with 95\% CIs, and statistical significance declared at $p$-value $<0.05$.

\section{Results}

\section{Socio-demographic characteristics}

Overall, 432 mother-newborn-pairs were involved in the study with a response rate of $95.8 \%$. About nine in ten, 387 (89.6\%) were aged 20-34 years. The majority 374 (86.6\%) had some level of formal education and 187 (43. $3 \%)$ were housewives. About two-third, 291(67.4\%) were urban and a third were rural residents (Table 1).

\section{Maternal obstetric and health service utilization}

One hundred eighty (41.7\%) of mothers were primiparous. About a third, 83 (32.9\%) of the women gave birth to the current newborn within two years $(\leq 24$ months) after a previous child birth. Thirty four mothers (7.9\%) had previous abortion and 18 (4.2\%) had still birth. One hundred twenty-five (28.9\%) mothers had some medical problems during recent pregnancy. The majority, 396 (91.7\%) had at least a visit for antenatal during recent pregnancy; 376 (94.9\%) of made their first visit during first trimester of gestation. A little higher than half, 210 (53\%) had at least four ANC visits and 290 (73.2\%) mothers affirmed for getting dietary advice during ANC follow-up (Table 2).

\section{Maternal nutritional status}

Based on current findings, 166 (38.4\%) mothers had MUAC less than $23 \mathrm{~cm}$ (undernourished). Three hundred fifty-five (92\%) took iron and folic acid supplements at least once and 264 (61.1\%) got less than 90 tablets during recent pregnancy. About two-third, 293 (67.8\%) consumed at least one additional meal to their usual meals. Mothers involved in this study frequently consumed cereals 258 (59.7\%) from food groups (Table 3).

\section{Proportion and predictors of term low birth weight}

The proportion of term low birth weight in this study was 8 . $1 \%$ (35/432). The mean weight of the newborns was $3532 \mathrm{~g}$ with standard deviation of 565 . Mothers with less formal educational status and housewives had about six times at higher risk of giving birth to low birth weight newborns $(\mathrm{AOR}=5.86 ; 95 \% \mathrm{CI}: 1.64,20.9)$ and $(\mathrm{AOR}=5.41 ; 95 \% \mathrm{CI}$ : 1.37,21.3). Mothers who consumed fruits rarely (less frequent than daily) had also a higher risk to give birth to term
Table 1 Socio-demographic characteristics of mothers and newborns involved in low birth weight study in health facilities at Wolaita Sodo town in South Ethiopia, March 2016

\begin{tabular}{|c|c|c|c|}
\hline Variables $(n=432)$ & & Frequency & Percent \\
\hline \multirow[t]{3}{*}{ Age } & $<20$ & 24 & 5.6 \\
\hline & $20-34$ & 387 & 89.6 \\
\hline & $35+$ & 21 & 4.9 \\
\hline \multirow[t]{2}{*}{ Marital status } & Married & 408 & 94.4 \\
\hline & Unmarried & 24 & 5.6 \\
\hline \multirow[t]{4}{*}{ Educational status } & No formal education & 58 & 13.4 \\
\hline & Primary School (1-8) & 143 & 33.1 \\
\hline & $\begin{array}{l}\text { Secondary School } \\
(9-12)\end{array}$ & 119 & 27.5 \\
\hline & College and above & 112 & 25.9 \\
\hline \multirow[t]{5}{*}{ Occupation } & Housewife & 187 & 43.3 \\
\hline & Government employee & 89 & 20.6 \\
\hline & Private employee & 32 & 7.4 \\
\hline & Merchant & 92 & 21.3 \\
\hline & Others $^{a}$ & 32 & 7.4 \\
\hline \multirow[t]{2}{*}{ Residence } & Rural & 141 & 32.6 \\
\hline & Urban & 291 & 67.4 \\
\hline \multirow[t]{4}{*}{ Average monthly income } & $\leq 810(\$ \leq 37.5)$ & 33 & 7.6 \\
\hline & $810-1296(\$ 37.5-60)$ & 112 & 25.9 \\
\hline & $1297-2591(\$ 61-120)$ & 121 & 28 \\
\hline & $\geq 2592(\$ \geq 120)$ & 166 & 38.4 \\
\hline \multirow[t]{2}{*}{ Sex of the newborn } & Male & 222 & 51.4 \\
\hline & Female & 210 & 48.6 \\
\hline
\end{tabular}

${ }^{\mathrm{a} S t u d e n t s, ~ d a i l y ~ l a b o u r e r s ~}$

LBW (AOR 13.9; 95\% CI: 2.29, 84.6). On the other hand, rural residents had a lower risk of giving birth to low birth weight newborns as compared to those from the nearby urban dwellers $(\mathrm{AOR}=0.06$; $(95 \% \mathrm{CI}=0.006,0.6)$ (Table 4).

\section{Discussion}

Evidence shows that birth weight is a good summary measure of multifaceted public health problems. Thus often used to indicate long-term maternal malnutrition, ill health, and poor health care during pregnancy [8]. This study documented that about $8.1 \%$ of term childbirths in government health facilities in Wolaita Sodo town ended up with low birth weight during the study period.

We observed a slightly lesser proportion of LBW in current study as compared to similar studies in Northern Ethiopia (10\%) and elsewhere (10.6\%) [28, 29]. It was also lower than similar study findings from Pakistan (9.9\%) and Kenya (12.3\%) [5, 30]. The main possible reason for the slight variation might be due to our exclusion of preterm newborns; whereas, the above studies included preterm babies. Conversely, we found a higher proportion 
Table 2 Obstetric history, morbidity and health service utilization of mothers who visited health facilities for child birth at Wolaita Sodo town in South Ethiopia, March 2016

\begin{tabular}{|c|c|c|c|}
\hline Variables $(n=432)$ & & Frequency & Percentage \\
\hline \multirow[t]{3}{*}{ Parity } & 1 & 180 & 41.7 \\
\hline & $2-4$ & 223 & 51.6 \\
\hline & $5+$ & 29 & 6.7 \\
\hline \multirow[t]{2}{*}{ Birth interval in months } & $\leq 24$ & 83 & 32.9 \\
\hline & $>24$ & 169 & 67.1 \\
\hline \multirow[t]{2}{*}{ History of abortion } & Yes & 34 & 7.9 \\
\hline & No & 398 & 92.1 \\
\hline \multirow[t]{2}{*}{ History of stillbirth } & Yes & 18 & 4.2 \\
\hline & No & 414 & 95.8 \\
\hline \multirow{3}{*}{$\begin{array}{l}\text { History of having small } \\
\text { baby }\end{array}$} & Yes & 0 & 0 \\
\hline & No & 391 & 90.5 \\
\hline & Not specified & 41 & 9.5 \\
\hline \multirow{2}{*}{$\begin{array}{l}\text { Medical IIInesses during } \\
\text { pregnancy }\end{array}$} & Yes & 125 & 28.9 \\
\hline & No & 307 & 71.1 \\
\hline \multirow[t]{2}{*}{ History of hypertension } & Yes & 8 & 1.9 \\
\hline & No & 424 & 98.1 \\
\hline \multirow[t]{2}{*}{ History of diabetes mellitus } & Yes & 4 & 0.9 \\
\hline & No & 428 & 99.1 \\
\hline \multirow{2}{*}{$\begin{array}{l}\text { ANC visits for recent } \\
\text { pregnancy }\end{array}$} & Yes & 396 & 91.7 \\
\hline & No & 36 & 8.3 \\
\hline \multirow[t]{2}{*}{ ANC visits } & $1-3$ & 186 & 47.0 \\
\hline & $4+$ & 210 & 53.0 \\
\hline \multirow{2}{*}{$\begin{array}{l}\text { Trimester for the first ANC } \\
\text { visit }\end{array}$} & $1 \mathrm{st}$ & 376 & 94.9 \\
\hline & $3 r d$ & 20 & 5.1 \\
\hline \multirow{2}{*}{$\begin{array}{l}\text { Dietary counselling during } \\
\text { ANC visit }\end{array}$} & Yes & 290 & 73.2 \\
\hline & No & 106 & 26.8 \\
\hline
\end{tabular}

of Term LBW compared to other studies in Ethiopia (6. $3 \%)$, Iran (6.8\%), and Egypt (7.3\%) [10, 11, 31, 32].

In consistent with studies from India, Tanzania, and Sudan, lower level of maternal education was documented in this study as a positive predictor of low birth weight $[4,6,33]$. A better formal education might have improved mothers' perceptions and dispositions in proper dietary habits during pregnancy and health service utilization. On the other hand, it might be assumed that the less educated would tend to be less informed on key dietary recommendations and health care during pregnancy [34].

Unlike many other study findings, this study documented that rural residents had a lower risk to have low birth weight babies as compared to those from nearby urban settings. This finding disagrees with similar study findings from Tigray (Northern Ethiopia) and Bale (South east Ethiopia) hospitals in Ethiopia [10,11,35] and also findings from Ghana [36].These might possibly be due to less
Table 3 Dietary intake and supplements pregnancy, and nutritional status of mothers involved in the study at Wolaita Sodo town in South Ethiopia, March 2016

\begin{tabular}{|c|c|c|c|}
\hline Variables $(n=432)$ & & Frequency & Percent \\
\hline \multirow[t]{2}{*}{ Cereals } & Yes & 258 & 59.7 \\
\hline & No & 174 & 40.3 \\
\hline \multirow[t]{2}{*}{ Starchy roots and tubers } & Yes & 47 & 10.9 \\
\hline & No & 385 & 89.1 \\
\hline \multirow[t]{2}{*}{ Legumes } & Yes & 91 & 21.1 \\
\hline & No & 341 & 78.9 \\
\hline \multirow[t]{2}{*}{ Dairy products } & Yes & 34 & 7.9 \\
\hline & No & 398 & 92.1 \\
\hline Meat & No & 432 & 100 \\
\hline Fish and poultry & No & 432 & 100 \\
\hline \multirow[t]{2}{*}{ Vegetables } & Yes & 38 & 8.8 \\
\hline & No & 394 & 91.2 \\
\hline \multirow[t]{2}{*}{ Fruits and nuts } & Yes & 43 & 10.0 \\
\hline & No & 389 & 90.0 \\
\hline \multirow[t]{2}{*}{ Egg } & Yes & 2 & 0.5 \\
\hline & No & 430 & 99.5 \\
\hline \multirow{2}{*}{$\begin{array}{l}\text { Additional meal during } \\
\text { pregnancy }\end{array}$} & Yes & 293 & 67.8 \\
\hline & No & 139 & 32.2 \\
\hline \multirow[t]{2}{*}{ Took iron supplements } & Yes & 355 & 92.0 \\
\hline & No & 31 & 8.0 \\
\hline \multirow{3}{*}{$\begin{array}{l}\text { Number of iron tablets } \\
\text { taken }\end{array}$} & $<90$ & 264 & 61.1 \\
\hline & $90-180$ & 91 & 21.1 \\
\hline & Unknown & 77 & 17.8 \\
\hline \multirow[t]{2}{*}{ MUAC of the mother } & $<23 \mathrm{~cm}$ & 166 & 38.4 \\
\hline & $23+\mathrm{cm}$ & 266 & 61.6 \\
\hline
\end{tabular}

representation of our sample for rural and urban groups which made our finding with a higher uncertainty (a very wide confidence interval for AORs). It might also be due to socioeconomic and other differences. The current finding agrees with a study in Jimma west Ethiopia which could be homogenous in many aspects to our settings [13].

Housewives had much higher odds of giving birth to low birth weight babies as compared to those who had some occupational engagements. This finding is in difference with similar studies South East in Ethiopia as well as Tanzania $[6,34,35]$. On the other hand, in favour of our finding, a study from Iran revealed an increased risk of low birth weight among housewives as compared to employees [37]. This might imply that housewives are mostly less educated, and often disadvantaged in accessing relevant health messages $[7,8,11]$. This might have affected their perceptions in dietary preferences and health service utilization. Furthermore, our study setting, Wolaita area is known for asset poverty; many households in the area are often food insecure [17, 20]. 
Table 4 Factors associated with low birth weight among term newborns in health facilities at Wolaita Sodo town in South Ethiopia, March 2016

\begin{tabular}{|c|c|c|c|c|}
\hline \multirow[t]{2}{*}{ Variables $(n=432)$} & \multicolumn{2}{|l|}{ LBW } & \multirow[t]{2}{*}{ COR $(95 \% \mathrm{Cl})$} & \multirow[t]{2}{*}{ AOR $(95 \% \mathrm{Cl})$} \\
\hline & Yes (\%) & No (\%) & & \\
\hline \multicolumn{5}{|l|}{ Age } \\
\hline$<25$ & $11(11.2)$ & $87(88.8)$ & $1.63(0.77,3.46)$ & $1.53(0.31,7.49)$ \\
\hline $25+$ & $24(7.2)$ & $310(92.8)$ & 1 & 1 \\
\hline \multicolumn{5}{|l|}{ Marital status } \\
\hline Married & $30(7.4)$ & $378(92.6)$ & $0.30(0.10,0.86)$ & $0.08(0.006,1.18)$ \\
\hline Other & $5(20.8)$ & $19(79.2)$ & 1 & 1 \\
\hline \multicolumn{5}{|l|}{ Educational status } \\
\hline Primary and below & $23(11.4)$ & $178(88.6)$ & $2.36(1.14,4.87)$ & $5.86(1.64,20.9)^{*}$ \\
\hline Secondary and above & $12(5.2)$ & $219(94.8)$ & 1 & 1 \\
\hline \multicolumn{5}{|l|}{ Occupation } \\
\hline Housewife & $20(10.8)$ & $166(89.2)$ & $2.08(1.03,4.22)$ & $5.41(1.37,21.3)^{*}$ \\
\hline Others & $15(6.1)$ & $231(93.9)$ & 1 & 1 \\
\hline \multicolumn{5}{|l|}{ Residence } \\
\hline Rural & $16(11.3)$ & $125(88.7)$ & $1.85(0.92,3.73)$ & $0.06(0.006,0.6)^{*}$ \\
\hline Urban & $19(6.5)$ & $272(93.5)$ & 1 & 1 \\
\hline \multicolumn{5}{|l|}{ Average monthly income } \\
\hline$\leq 810$ & $6(18.2)$ & $27(81.8)$ & $3.88(1.28,11.8)$ & $2.55(0.19,34.09)$ \\
\hline $810-1296$ & $12(10.7)$ & $100(89.3)$ & $2.09(0.85-5.15)$ & $0.88(0.09,8.02)$ \\
\hline $1297-2591$ & $8(6.6)$ & $113(93.4)$ & $1.23(0.46-3.30)$ & $2.44(0.61,9.69)$ \\
\hline$\geq 2592$ & $9(5.4)$ & $157(94.6)$ & 1 & 1 \\
\hline \multicolumn{5}{|l|}{ Parity } \\
\hline 1 & $22(12.2)$ & $158(87.8)$ & $2.56(1.25,5.23)$ & $1.95(0.47,7.99)$ \\
\hline $2+$ & $13(5.2)$ & $239(94.8)$ & 1 & 1 \\
\hline \multicolumn{5}{|l|}{ Medical conditions } \\
\hline Yes & $6(4.8)$ & $119(95.2)$ & 1 & 1 \\
\hline No & $29(9.4)$ & $278(90.6)$ & $2.07(0.84,5.11)$ & $0.67(0.18,2.52)$ \\
\hline \multicolumn{5}{|l|}{ Dietary counselling } \\
\hline Yes & $17(5.9)$ & $273(94.1)$ & 1 & 1 \\
\hline No & $12(11.3)$ & $94(88.7)$ & $2.05(0.94,4.45)$ & $3.08(0.64,14.77)$ \\
\hline \multicolumn{5}{|c|}{ Number of additional meals } \\
\hline 1 & $2(2.8)$ & $70(97.2)$ & 1 & 1 \\
\hline $2+$ & $21(9.5)$ & $200(90.5)$ & $3.67(0.84,16.07)$ & $3.5(0.55,22.59)$ \\
\hline \multicolumn{5}{|l|}{ Iron tablets consumed } \\
\hline$<90$ & $26(9.8)$ & $238(90.2)$ & $3.2(0.94,10.85)$ & $0.56(0.13,2.46)$ \\
\hline$\geq 90$ & $3(3.3)$ & $88(96.7)$ & 1 & 1 \\
\hline \multicolumn{5}{|l|}{ MUAC } \\
\hline$<23 \mathrm{~cm}$ & $15(9)$ & $151(91)$ & $1.22(0.61,2.46)$ & $3.15(0.95,10.44)$ \\
\hline$\geq 23 \mathrm{~cm}$ & $20(7.5)$ & $246(92.5)$ & 1 & 1 \\
\hline \multicolumn{5}{|l|}{ Cereals } \\
\hline Daily & $27(10.5)$ & $231(89.5)$ & 1 & 1 \\
\hline < Daily & $8(4.6)$ & $166(95.4)$ & $2.42(1.07,5.47)$ & $2.89(0.66,12.74)$ \\
\hline \multicolumn{5}{|l|}{ Fruits } \\
\hline Daily & $9(20.9)$ & $34(79.1)$ & 1 & 1 \\
\hline$<$ Daily & $26(6.7)$ & $363(93.3)$ & $3.69(1.60,8.52)$ & $13.9(2.29,84.6)^{*}$ \\
\hline
\end{tabular}


Mothers who did not consume fruits daily during pregnancy had much higher odds of giving birth to low birth weight as compared to those who did so. This was in agreement with a similar study in Nepal [38]. This might be due to a complementary nutritional benefits of fruits as main food sources for micronutrients; thus if particularly consumed in the first trimester, they could enhance organ development for the foetus. Some studies elsewhere in Ethiopia, Bangladesh, Indonesia and Nepal have documented a significant association between low MUAC measures of mothers and term low birth weight in their newborns [11, 39]; however our data did not imply such association. We recommend further studies to evaluate the effect of maternal undernutrition on newborn birth weight.

\section{Study limitations}

This study was limited to health facilities in scope and used a crossectional data. Thus mainly maternal side predictors of term low birth weight were assessed. Moreover, the time allotted for recruiting participants was limited though we assumed standard procedures of sample size calculation. The estimate might be better representative if a longitudinal follow-up data were used. Certain level of recall bias was expected with regard to menstrual dates and dietary habits; health workers conscious on cultural issues collected the data to reduce recall bias. Though all mothers attending delivery service with ANC follow up were ahead screened for HIV, we could not access this information due to limitations out of our scope. We have no data on other covariates such as food security and a reliable wealth data.

\section{Conclusions}

Though it would or would not be possible to bring all child bearing or potential mothers with less education to school; alternative opportunities of empowering women could be done. Occupational engagements of the women might also contribute to empower them on decision making capacities particularly on diet and health care.

Skilled counselling to diet during pregnancy including intake of fruits would benefit the women. Formal education when feasible and alternatively equivalent approaches targeting on diet and health care utilization would benefit. Moreover, we recommend community based data of birth weight through longitudinal studies for a better estimation of the prevalence of low birth weight.

\section{Additional file}

Additional file 1: Questionnaire: Term low birth weight study, Wolaita Sodo. (DOCX $23 \mathrm{~kb}$ )
IFA: Iron and folic acid; LBW: Low birth weight; MUAC: Mid-Upper Arm Circumference; NORHED: Norwegian Programme for Capacity Development in Higher Education and Research for Development; SENUPH: South Ethiopia Network of Universities in Public Health; SPSS: Statistical Package for Social Sciences; SSA: Sub-Saharan Africa; UoB: University of Bergen; WSU: Wolaita Sodo University

\section{Acknowledgements}

We would like to thank the SENUPH_NORHED project for granting the study. We are grateful to the School of Public Health at WSU for facilitating the research programme. We would like to thank Mr.Wondimagegn Paulos (a focal person for SENUPH project at WSU) for facilitating the research grant. We thank Wolaita Zone health department and the local authorities for official permissions and administrative supports. We acknowledge our responsible data collectors and supervisors. We are grateful to the consent and commitment of mothers involved in the study just after their childbirth without which this study would not be possible.

\section{Funding}

This study was financially supported by South Ethiopia Network Universities in Public Health SENUPH project from Norwegian Programme for Capacity Development in Higher Education and Research for Development (NORHED).Wolaita Sodo University facilitated the funding through a graduate level research programme. Neither of the parties had roles in design, conduct and decision to publish this research work.

Availability of data and materials

The datasets analyzed for this study is available with corresponding author which can be accessed on reasonable request.

\section{Authors' contributions}

SK designed the protocol, coordinated data collection, made analysis and interpreted findings, and drafted the manuscript. TD contributed in design, analysis, interpretation of the findings, and reviewed the manuscript. BY contributed in design, analysis and interpretation of findings, reviewed progressive drafts, and proofread the manuscript. All authors read and approved the final version of the manuscript.

\section{Authors' information}

SK is a human nutritionist by training. He studied MSc in Human nutrition and currently working as lecturer in School of Public Health at Wolaita Sodo University (WSU) in Ethiopia. TD is Public Health nutritionist by training. He is an associate Professor in the school of Public at WSU. BY is a public Health specialist. He has been assistant Professor in the School of public health at WSU. He is currently a joint PhD Fellow at the Centre for International Health $(\mathrm{ClH})$ in the University of Bergen (UoB) in Norway and Hawassa University (Ethiopia).

\section{Ethics approval and consent to participate}

We obtained ethical clearance for the study from the ethical review committee at College of Health Sciences and Medicine in Wolaita Sodo University in Ethiopia. The committee justified for verbal informed consent in favour of many less educated mothers who would face difficulty in reading and comprehending the consent form. Moreover, those with less school grades could not be able to comprehend all issues in the document. Thus ethical clearance we obtained considered the least possible scenario and approved for verbal informed consent. The ethical clearance we obtained was written with a heading to Wolaita zone health department which is a higher government body in the area for health and health research conducts. Thus we got permission from this health department and its lower health administrative structures. Finally informed verbal consent was obtained from each participant. The data was made anonymous by identification numbers.

\section{Competing interests}

The authors declare that they have no competing interests.

\section{Publisher's Note}

Springer Nature remains neutral with regard to jurisdictional claims in published maps and institutional affiliations.
Abbreviations
ANC: Antenatal care; AOR: Adjusted Odds Ratio; BMI: Body mass index;
Cl: Confidence interval; CIH: Centre for International Health; COR: Crude odds
ratio; EDHS: Ethiopian Demographic and Health Survey; ETB: Ethiopian Birr; 


\section{Author details}

'School of Public Health, Wolaita Sodo University, Wolaita Sodo, Ethiopia. ${ }^{2}$ School of Public Health, Hawassa University, Hawassa, Ethiopia. ${ }^{3}$ Centre for International Health, University of Bergen, Bergen, Norway.

\section{Received: 13 March 2017 Accepted: 26 April 2018}

Published online: 11 May 2018

\section{References}

1. WHO and UNICEF. In: E.a.P. section, editor. Low birth weight country, regional and global estimates. New York: WHO; 2004

2. Sutan $\mathrm{R}$, et al. Determinants of low birth weight infants: a matched case control study. Open J Prev Med. 2014:4:91-9.

3. UNICEF. In: R.a.P. Data and Analytics Section; Division of Data, editor. Low birth weight: percentage of infants weighing less than 2,500 grams at birth; 2014.

4. Saeed OAM, et al. Risk factors of low birth weight at three hospitals in Khartoum state, Sudan. Sudanese J Paediatr. 2014;14(2):22-8.

5. Muchemi OM, Echoka E, Makokha A. Factors associated with low birth weight among neonates born at Olkalou District Hospital, Central Region, Kenya. Pan Afr Med J 2015;20(108).

6. Siza JE. Risk factors associated with low birth weight of neonates among pregnant women attending a referral hospital in northern Tanzania. Tanzania J Health Res. 2008;10(1).

7. CSA, Ethiopia demographic and health survey. 2011.

8. [Ethiopia], C.S.A.C. and ICF. Ethiopia demographic and health survey 2016. In: Final report. Addis Ababa, Rockville: Central Statistical Authority; 2017.

9. Zeleke BM, Zelalem M, Mohammed N. Incidence and correlates of low birth weight at a referral hospital in Northwest Ethiopia. Pan Afr Med J. 2012;12(4).

10. Teklehaimanot N, Hailu T, Assefa H. Prevalence and factors associated with low birth weight in Axum and Laelay Maichew districts, North Ethiopia: a comparative cross sectional study. Int J Nutr Food Sci. 2014;3(6):560-6.

11. Gebremedhin M, et al. Maternal associated factors of low birth weight: a hospital based cross-sectional mixed study in Tigray, Northern Ethiopia. BMC Pregnancy Childbirth. 2015;15(222).

12. Assefa N, Berhane $Y$, Worku A. Wealth status, Mid Upper Arm Circumference (MUAC) and Antenatal Care (ANC) are determinants for low birth weight in Kersa, Ethiopia. PLoS One. 2012:7(6)

13. Tema T. Prevalence and determinants of low birth weight in Jimma zone, Southwest Ethiopia. East Afr Med J. 2006;83(7):366-71.

14. Leza T, Kuma B. Determinants of rural farm household food security in Boloso Sore District of Wolaita Zone in Ethiopia. Asian J Agric Ext Econ Sociol. 2015;5.

15. Feyisso $M$, et al. Differentials of modern contraceptive methods use by food security status among married women of reproductive age in Wolaita zone, South Ethiopia. Arch Public Health. 2015;73:38.

16. Abo T, Kuma B. Determinants of food security status of female-headed households: the case of Wolaita Sodo town, South Nations, Nationalities and Peoples Region, Ethiopia. Int J Sci Foot Prints. 2015;3.

17. Gecho Y, et al. Livelihood strategies and food security of rural households in Wolaita Zone, Southern Ethiopia. Dev Country Stud. 2014;4(14).

18. Bogale Gebeyehu GR, Tebeje M. Rural households food security and livelihood strategies: the case of Offa woreda, in wolaita Sodo Zuria, Southern Nation, Nationalities and Peoples Regional State, Ethiopia. IJRESS. 2014;4.

19. Eneyew A, Bekele W. Causes of household food insecurity in Wolaita: Southern Ethiopia. J Stored Prod Postharvest Res. 2012;3.

20. Ayele T. Livelihood adaptation, risks and vulnerability in rural Wolaita, Ethiopia. In: Department of International Environment and Development Studies. Norway: Noragric Norwegian University of Life Sciences, UMB; 2008. p. 164

21. Ethiopian Minstery of Health. In: R. Health, editor. Community based new born care implementation plan. Addis Ababa, Ethiopia. Addis Ababa: Federal Ministry of Health in Ethiopia; 2013.

22. Wardlaw GM, Hampl JS. Perspectives in Nutrition. 7th ed. New York: McGraw Hill; 2007.

23. Ethiopia, M.o.H.o., National Nutriton Programme. 2016.

24. Plessis LMd, Naude CE. Community nutrition textbook for developing countries. 2008.

25. Yaya $\mathrm{S}$, et al. Timing and adequate attendance of antenatal care visits among women in Ethiopia. PLoS One. 2017;12(9):e0184934.

26. Lindtjørn B, et al. Reducing maternal deaths in Ethiopia: results of an intervention programme in Southwest Ethiopia. PLoS One. 2017;12(1):e0169304.
27. Tang AM, et al. Determining a global mid-upper arm circumference cutoff to assess malnutrition in pregnant women. Washington, DC: FHI 360/Food and Nutrition Technical Assistance III Project (FANTA); 2016.

28. Gebregzabiherher $Y$, et al. The Prevalence and risk Factors for Low Birth Weight among Term Newborns in Adwa General Hospital, Northern Ethiopia. Obstet Gynecol Int. 2017;2017.

29. Khan A, Nasrullah FD, Jaleel R. Frequency and risk factors of low birth weight in term pregnancy. Pak J Med Sci. 2016;32(1):138-42.

30. Badshah S, et al. Risk factors for low birth weight in the public hospitals at Peshawar, Pakistan. BMC Public Health. 2008;4(8):197.

31. Jafari F, et al. Socio-economic and medical determinants of low birth weight in Iran: 20 years after establishment of a primary healthcare network Public Health. 2010;124(3):153-8.

32. Hong R, Ruiz Beltran M. Low birth weight as a risk factor for infant mortality in Egypt. East Mediterr Health J. 2008;14(5):992-1002.

33. Metgud CS, Naik VA, Mallapur MD. Factors Affecting Birth Weight of a newborn A community Based Study in Rural Karnataka, India. PLoS One. 2012;7(7).

34. Ezugwu EC, et al. Singleton low birth weight babies at a Tertiary hospital in Enugu, South East Nigeria. Int J Gynaecol Obstet. 2009;14(1).

35. Demelash $\mathrm{H}$, et al. Risk factors for low birth weight in Bale zone hospitals, SouthEast Ethiopia: a case-control study. BMC Pregnancy Childbirth. 2015;15(264).

36. Kayode GA, et al. Contextual risk factors for low birth weight: a multilevel analysis. PLoS One. 2014;9(1)

37. Khojasteh $\mathrm{F}$, et al. The relationship between maternal employement status and pregnancy outcomes. Global J Health Sci. 2015;8(9).

38. Osrin $\mathrm{D}$, et al. Effects of antenatal multiple micronutrient supplementation on birthweight and gestational duration in Nepal: double blind, randomised controlled trial. Lancet. 2005;365:955-62.

39. Islam $M$, et al. Effect of maternal status and breastfeeding practices on infant nutritional status - a cross sectional study in the south-west region of Bangladesh. Pan Afr Med J. 2013;16:139.

\section{Ready to submit your research? Choose BMC and benefit from:}

- fast, convenient online submission

- thorough peer review by experienced researchers in your field

- rapid publication on acceptance

- support for research data, including large and complex data types

- gold Open Access which fosters wider collaboration and increased citations

- maximum visibility for your research: over $100 \mathrm{M}$ website views per year

At BMC, research is always in progress.

Learn more biomedcentral.com/submissions 